\title{
A PAISAGEM AGRESTE DE CORRENTES-PE ATRAVÉS DO VERDE DE QUINTAIS, JARDINS E CALÇADAS.
}

\author{
Ana Maria Severo Chaves
}

\author{
Maria Betânia Moreira Amador
}

RESUMO: As áreas urbanas têm nos elementos verdes um dos alicerces de bem estar, conforto beleza e valorização econômica, onde o homem é o principal beneficiado. Assim, no momento de pesquisar a importância e utilização da massa verde urbana deve-se levar em consideração todo espaço com tal massa. Apesar de a pesquisa dar ênfase aos espaços verdes residenciais como quintais, jardins e calçadas no município de Correntes-PE, seguindo-se a linha de pesquisa sistêmica onde, ao mesmo tempo em que se estudaram os espaços evidenciados teve-se, também, a visão voltada à compreensão da relação do residente com o verde de sua casa, a interação desse verde com espaços como praças e canteiros centrais. O objetivo da pesquisa foi averiguar o verde existente em quintais, jardins e calçadas em ruas e avenidas do município de Correntes-PE, diagnosticando-se como os moradores cuidam de seus jardins, quintais e árvores desses espaços considerados, quais os cuidados com a arborização de suas casas e qual relação e importância há entre o verde e os residentes das casas visitadas. A metodologia foi inicialmente o levantamento bibliográfico, registros fotográficos, os quais foram associados com as observações e entrevistas realizadas, complementando-se com a formulação de tabelas e apuração estatística para analisar os dados adquiridos. Teve-se como resultado as diversas percepções sobre a importância da vegetação/arborização para os residentes e a residência, qual utilização dada aos espaços destinados a quintais jardins e calçadas, o quanto os moradores são desinformados sobre as utilizações e importância do verde urbano, o que se acredita ser um caminho que aponta para a necessidade da realização de palestras e debates na cidade sobre o estudo e resultados adquiridos e problemas vivenciados por todo do município.

Palavras chave: Visão sistêmica. Verde urbano. Geografia.

\section{INTRODUÇÃO}


O verde urbano vem sendo cada vez mais citado em trabalhos acadêmicos e debates, principalmente referente à qualidade de vida urbana, já que a presença da massa verde nos centros urbanos é um elemento que proporciona beleza, bem estar, lazer e valorização econômica em espaços com tal presença.

Esse trabalho focou, principalmente, o Verde Urbano presente em residências do Município Correntes situado no agreste pernambucano, componente do semiárido nordestino. Por se tratar de uma pesquisa que envolveu estudo de campo e bibliográfico, no âmbito metodológico optou-se pelo total de 10 locais de estudos, entre ruas e avenidas para a observação in loco e entrevistas abertas aos residentes.

As ruas escolhidas foram: Avenida Raimundo Calado, Rua Francisco de Assis, Rua Praça Agamenon Magalhães, Rua Barão de Lucena, Rua João de Deus Neto, Rua José Francisco dos Santos, Rua Quintino Bocaiúva, Avenida Cursino Jacobina, Rua Joaquim Nabuco e Rua Coronel Francisco Santos, que não foram escolhidas aleatoriamente, porém fazem parte tanto das áreas centrais do município como das áreas mais afastadas.

Ao falar em verde residencial se faz análise sobre os espaços presentes nas casas urbanas que, entre suas finalidades, uma delas seja a presença da arborização e/ou vegetação, diagnosticando-se que independente das pessoas que cultivam plantas ornamentais em vasos e caqueras, os espaços destinados a tal fim são os quintais, jardins e calçadas.

Esses espaços, então, são denominados "espaços construídos" que, segundo Eric Dardel, "A Geografia encontra um espaço construído, um espaço que é obra do homem [...] a forma mais importante do espaço construído está ligado ao habitat do homem" (DARDEL, 2011, p. 27). Assim leva-se em consideração que todo ser vivo depende de um abrigo para sua sobrevivência, e é no lar que o homem constrói e se constrói, realiza e se realiza. Faz uso de lugares que ele próprio constrói para si, um espaço que lhe permita ter segurança, lazer e bem estar, adjetivos esses também presentes em ambientes com a presença do verde. 
ambiente vivido, procurou-se identificar tanto problemas de ordem física quanto social que interferem na presença da vegetação arbórea ou não da cidade em estudo.

Deve-se, também, considerar que a população nem sempre percebe ou sabe valorizar a importância e beneficies do verde em suas residências. Por falta de conhecimento ou planejamento, acaba associando os elementos verdes de seu lar a algo desnecessário e/ou até mesmo perigoso, acrescentando-se, ainda, a falta de planejamento urbano do município, o déficit relacionado à vegetação, principalmente em relação à arborização das calçadas que só tende a agravar-se.

\section{CORRENTES-PE}

O município de Correntes está localizado na Mesorregião Agreste e na Microrregião de Garanhuns do Estado de Pernambuco, limitando-se a norte com Garanhuns e Palmeirina, a sul e leste com Estado das Alagoas, e a oeste com Lagoa do Ouro. A área municipal ocupa $284,1 \mathrm{~km} 2$ e representa $0.29 \%$ do Estado de Pernambuco. A sede do município tem uma altitude, aproximada de 391 metros e coordenadas geográficas de 09 07' 44" de latitude sul e 3619' 49" de longitude oeste (figura 1). 
<smiles>FC1NC2NC1S2</smiles><smiles>C=CCCCC</smiles>

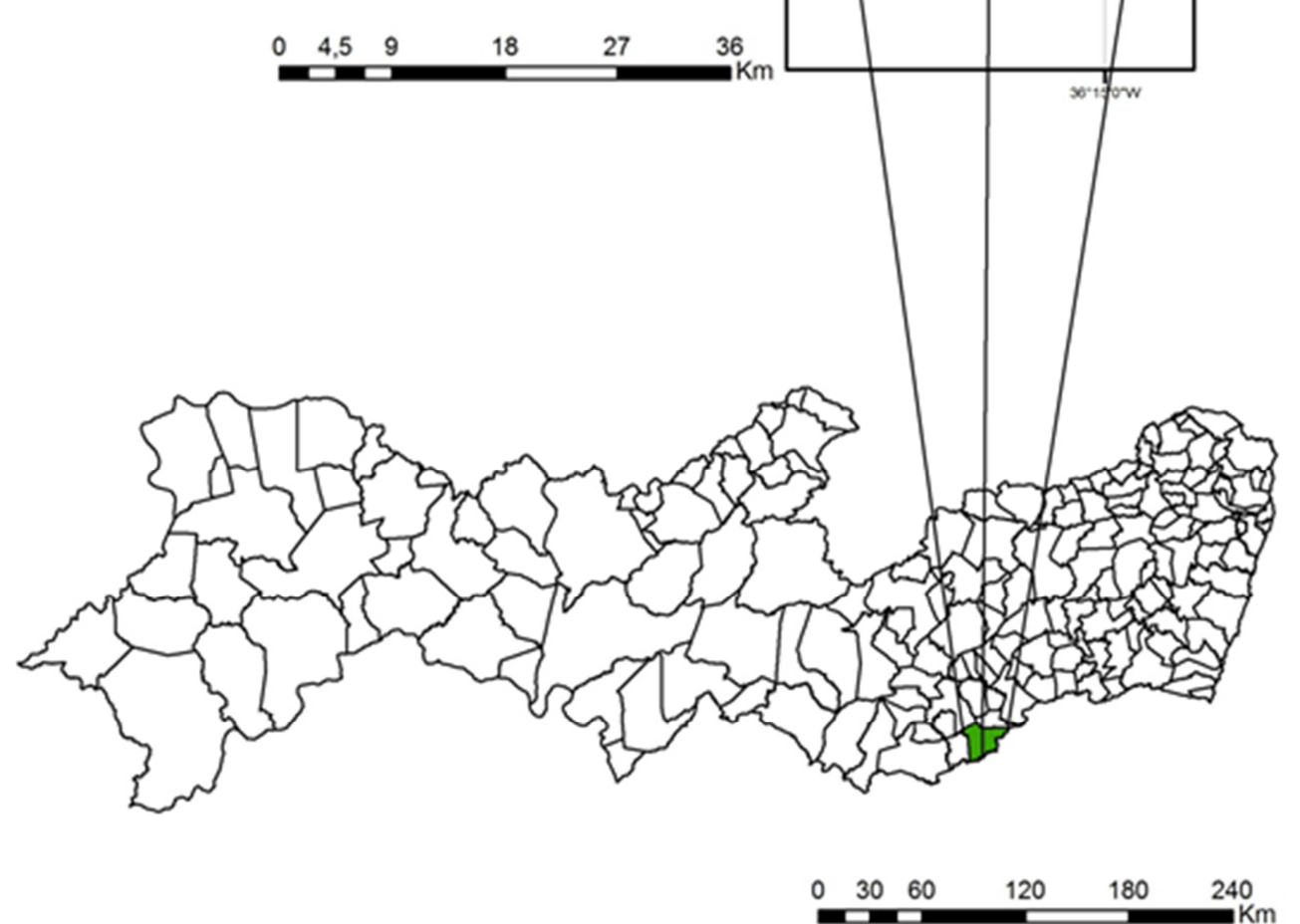

\section{Legenda}

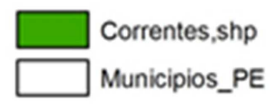

Figura 1: Mapa da localização do Município Correntes-PE. Adaptado por Chaves 2013

O município tem sua economia baseada na agricultura, pecuária e comércio em geral, além de outras atividades. A cidade surgiu às margens do Rio Correntes e do Rio Mundaú. Tem-se noticia de que os primeiros moradores usavam de forma direta a água 


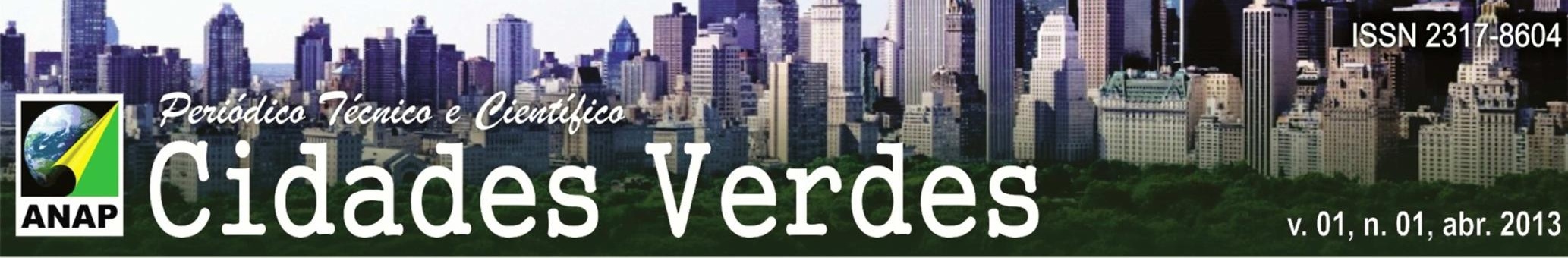

A Rua José Francisco dos Santos, além de ser pequena é estreita. Boa parte das casas não têm calçadas e nenhuma árvore nas mesmas. De um lado da rua, as casas não tem quintais, apenas uma pequena área de serviço e, do outro lado, além das árvores e plantas presentes nos quintais é comum a criação animais como galinhas.

Na Rua Quintino Bocaiúva observou-se que apresenta um canteiro central com arborização deficiente. Há árvores em algumas calçadas apesar das mesmas serem desorganizadas em termos de largura e altura. Das casas entrevistadas apenas duas possuem jardins e, apenas duas não possuem quintais.

A Rua Cursino Jacobina, possui esse nome devido à pracinha localizada no centro da mesma com árvores grandes e um símbolo religioso, ou seja, uma estátua de Padre Cícero. As sombras dessas árvores são grandes e chegam até as calçadas de algumas casas nas imediações. Assim, alguns moradores alegam não precisarem plantar árvores nas calçadas porque as árvores da praça já fornecem a sombra necessária. Observou-se, ainda, que algumas casas não possuem quintais e sofrem com a falta de saneamento básico e, quando chove muito o terreno por trás dessas casas acabam alagado com água da chuva e esgoto. Mas também, há casas com quintais enormes comportando uma significativa diversificação em termos de pomar e só uma casa apresentou-se com um pequeno jardim.

A Rua Joaquim Nabuco não tem canteiro central, mas algumas calçadas são arborizadas. Porém, muitos moradores acabaram sacrificando suas árvores por medo da fiação elétrica da cidade que é baixa podendo causar algum acidente, além da falta de assistência do governo local na manutenção das árvores, o que só contribui para a erradicação das mesmas.

Já na Rua Coronel Francisco Santos viu-se que se apresenta com um pequeno canteiro central e boa parte das casas possui quintal grande com a função principal do cultivo de frutíferas. E, apesar de todas as casas possuírem calçadas, poucas possuem árvores. Nenhuma casa tem jardim por falta de espaço, mas boa parte dos moradores cultivam plantas ornamentais, flores e outras plantas como ervas medicinais em caqueras ou vasos. 
A falta de planejamento urbano faz de Correntes uma cidade com problemas estruturais, principalmente no que se refere às ruas e calçadas. Devido ao fato de boa parte das calçadas serem estreitas e irregulares ficam livres da arborização porque "A arborização urbana não significa apenas plantar árvores, mas segue uma série de atividades como manutenção e gerenciamento do patrimônio vegetal, cabendo aos órgãos públicos criar os meios que viabilizem a sua execução" (NETO; SOUZA, 2009, p 57). E, além da espécie arbórea que deve ser adequada para a calçada tem-se que levar em consideração o espaço e objetos aéreos e terrestres como o tamanho das calçadas que se pretende arborizar.

\subsection{ARBORIZAÇÃO DE QUINTAIS JARDINS E CALÇADAS}

No momento em que se decide falar em arborização urbana se dá ênfase a três espaços distintos, quais sejam: quintais, jardins e calçadas. Leva-se em consideração que esses espaços verdes, especificamente quintais e jardins são locais privados. Mas, no momento em que estes locais estão inseridos na área urbana, interagem na paisagem ao se integrarem ao verde de praças, canteiros centrais, logradouros e calçadas dando a conotação da massa verde urbana; verde esse que proporciona benefícios à população em geral, principalmente quando está inserida no planejamento urbano, como é citado por Santos.

\footnotetext{
A arborização é essencial a qualquer planejamento urbano e tem funções importantíssimas como: propiciar sombra, purificar o ar, atrair aves, diminuir a poluição sonora, constituir fator estético e paisagístico, diminuir o impacto das chuvas, contribuir para o balanço hídrico, valorizar a qualidade de vida local, assim como economicamente as propriedades ao entorno. (SANTOS, 2001, p. 2)
}

Visto que apenas plantar árvore não resultaria em nenhum beneficio à vida urbana, pois após ela crescer pode acabar gerando transtornos e perigos para a população, é essencial que toda arborização urbana esteja dentro de um planejamento que leve em 
consideração leis e normas de segurança que garanta a boa utilização da mesma no futuro.

\subsection{QUINTAIS}

Os quintais são espaços de cunho familiar, onde se delineia um lugar com varias utilizações como o cultivo de espécies frutíferas, leguminosas e medicinais, e até mesmo criação de pequenos animais domésticos. Os quintais visitados por ocasião do estudo de campo, evidenciaram certa heterogeneidade, tanto no que se refere ao espaço que deveria ser um quintal é não o é, como no que tange as diversificações existentes na vegetação presente e, ainda, na associação à criação de animais como galinhas.

Citando Guimarães; Ambrósio apud Chaves; Amador, sobre estudos feitos sobre quintais, tem que,

[...] estudos distintos sobre a importância de quintais domésticos com relação à alimentação e rendas familiares, entre suas considerações ressaltam a importância do quintal para a diversificação dos alimentos presentes na alimentação diária. A ausência do quintal pode ser um fator de restrição da dieta, em especial dos alimentos fonte de vitaminas, minerais e fibras, como hortaliças e frutas. (GUIMARÃES; AMBRÓSIO Apud CHAVES; AMADOR, 2012).

Levando-se em conta que não é preciso comprar o que se pode produzir, percebese que cultivar frutíferas, hortaliças, entre outros, é uma boa maneira de complementar a renda familiar, ao mesmo tempo em que garante alimentos mais saudáveis.

Muitos dos entrevistados associam essa prática a algo muito trabalhoso e preferem dar ao espaço do quintal a função de área de serviço (figura 2) ou outra função. Mas em contrapartida, grande parte deles além das diversas espécies cultivadas, conseguem transformar o quintal em uma verdadeira lavoura com culturas temporárias como feijão e milho (figura 3), fato esse que demonstra o tradicionalismo de pessoas que já residiram na área rural. 

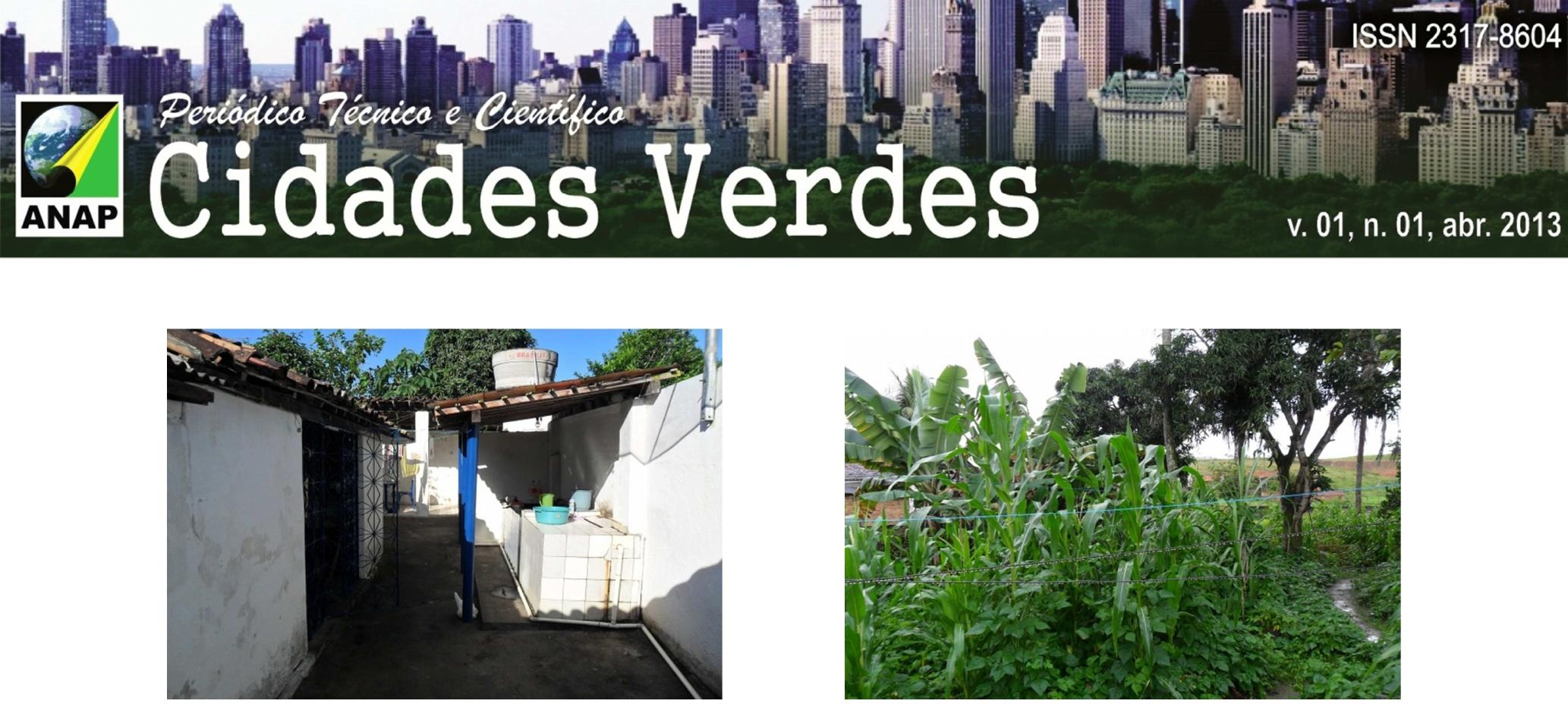

Figura 2 e 3: 2 espaço de quintal com função de área de serviço; 3 quintal no qual é cultivado culturas temporárias como milho e feijão. Fote: Pesquisa de campo 2012.

Há também quintais que funcionam como jardins. Vê-se assim, como determinado espaço tem diversas utilizações na visão de cada individuo.

\subsection{JARDINS}

Ter um jardim em casa requer um espaço, planejamento e gastos, artifícios que nem todo morador correntense dispõe. Assim, pode-se apreender uma pequena retrospectiva sobre esse espaço apresentada por De Angelis em Loboda:

O uso do verde urbano, especialmente no que diz respeito aos jardins, constitui-se em um dos espelhos do modo de viver dos povos que o criaram nas diferentes épocas e culturas. A princípio, estes tinham uma função de dar prazer à vista e ao olfato. Somente no século XIX é que assumem uma função utilitária, sobretudo nas zonas urbanas densamente povoadas. (LOBODA; DE ANGELIS, 2005 p. 126).

Os jardins deixam de ser vistos apenas na sua função estética passando também a serem valorizados por seus valores ambientais.

No município das Correntes, alvo desse estudo, verificou-se que os jardins são atrativos de poucas residências. Em sua maioria, os próprios donos das casas são os responsáveis por cuidarem de seus jardins. No entanto, as famílias que tem maiores condições financeiras e dão grande importância à estética de suas casas e jardins, 


\subsection{CALÇADAS}

As calçadas são espaços públicos, destinados ao trânsito de pedestre. Elas devem ter uma extensão que permita a passagem das pessoas sem obstáculos, livre de irregularidades, acessíveis aos portadores de mobilidade reduzida. Devem ser bem conservadas e o piso, preferencialmente, antiderrapante, permitindo que as pessoas possam caminhar com segurança. Deve, em essência, apresentar um percurso livre de obstáculos de forma compartilhada com os diversos usos e serviços, bem como ser uma área impermeável com a presença de vegetação principalmente árvores, desde que isso não interfira no transitar dos pedestres.

No estudo realizado, pode-se verificar que a arborização das calçadas correntenses é deficiente devido a vários problemas, como a irregularidade ou falta da própria calçada, fiação elétrica baixa e a plantação de espécies arbóreas inadequadas para calçadas residenciais. Assim, muitos cortam as árvores das calçadas porque estão muito próximas da fiação elétrica (figura 5); visualizaram-se danos estruturais na casa ou nas próprias calçadas por causa, acredita-se, das raízes das árvores; além de que a maioria das calçadas são estreitas, fazendo com que os pedestres transitem na via, considerando-se assim, a arborização como um empecilho (figura 6). 

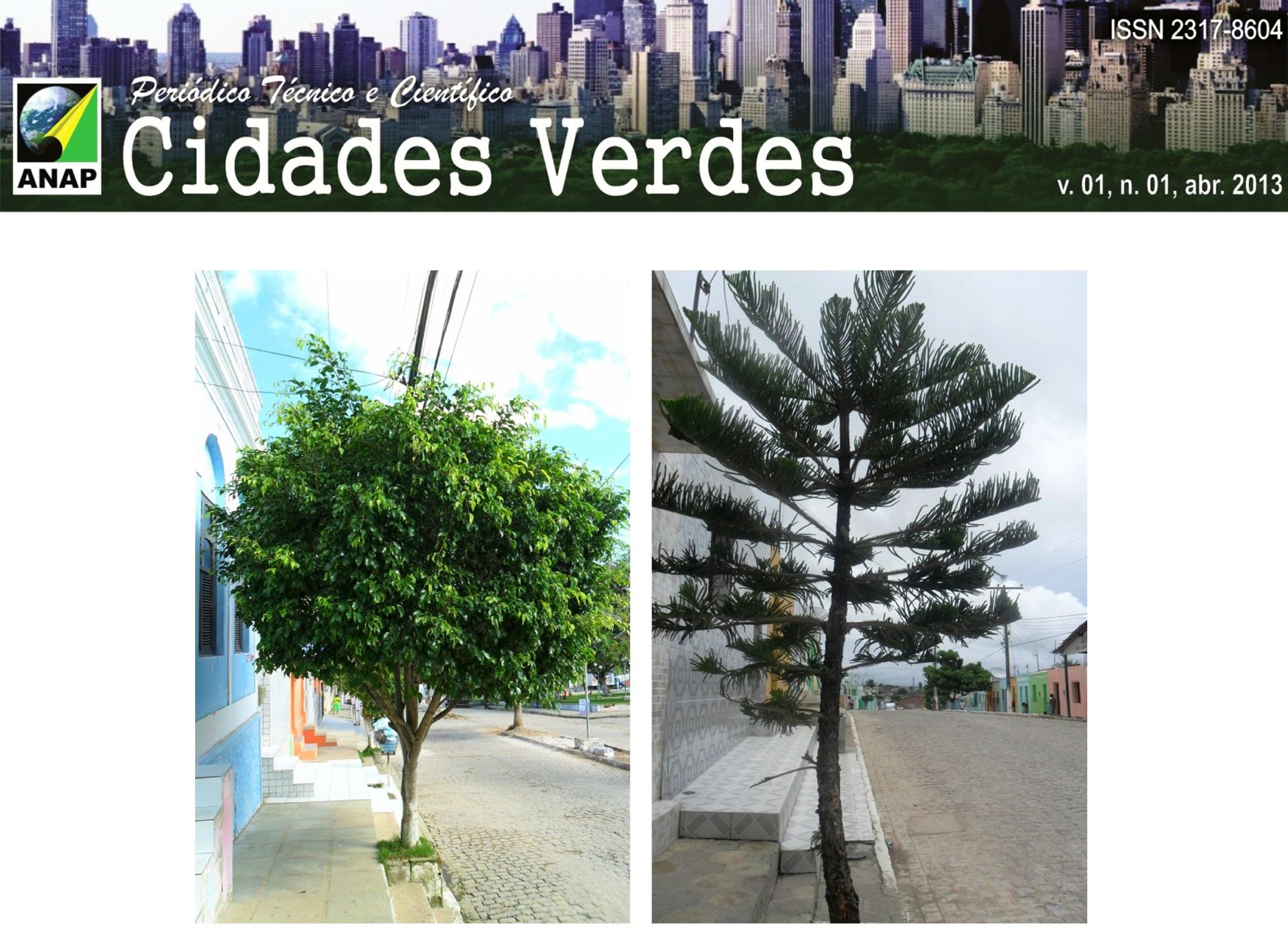

Figuras 5 e 6: 5 a fiação eletrica passou por entre os galhos da árvore; 6 a árvore plantada em uma calçada inrregular se torna um impecilho além de não ser uma especie adequda para calçada.

Fote: Pesquisa de campo 2012.

E, ao se falar em arborização de calçadas, se está diante de um pequeno dilema, pois estas fazem parte de debate entre os estudiosos do assunto sobre se podem ser consideradas como constituinte da área verde urbana. De acordo com Loboda; De Angelis, a arborização das calçadas, por estarem localizadas em local impermeável, não faria parte das áreas verdes. Seriam, apenas, integrantes da arborização urbana. Mas, se admitido que toda arborização ou vegetação de calçada, jardins ou quintais, junto às praças e canteiros centrais compõem a massa verde urbana, dever-se-ia considerar a arborização das calçadas como parte das áreas verdes urbanas conforme pode-se ver na citação de Antônio Silveira R. dos Santos,

[...] estas árvores estão protegidas pela legislação municipal contra cortes, de forma que sua localização acaba sendo perene, fortalecendo o entendimento de que compõem efetivamente a "massa verde urbana". Além disso, este tipo de 
arborização tem a finalidade de propiciar um equilíbrio ambiental entre as áreas construídas e o ambiente natural alterado. Para nós toda a vegetação existente na cidade deve ser considerada como área verde, inclusive as árvores de porte que estão nos quintais, ou seja, em áreas particulares. (SANTOS, 2001, p. 2).

Assim, na hora de plantar uma árvore, principalmente nas calçadas, devem-se considerar alguns fatores expressos na Cartilha de Arborização da Secretaria do Meio Ambiente, onde as calçadas devem ser arborizadas de acordo com o espaço aéreo e subterrâneo disponível. As principais questões que interferem na escolha das espécies para plantar em calçadas são: "A largura das calçadas; presença ou ausência de fiação aérea; tipo de fiação aérea (convencional, isolada ou protegida); recuo frontal das edificações". (SECRETARIA DO MEIO AMBIENTE, 2012, p 6). Fica evidente, então, que arborizar uma calçada não é apenas plantar árvore em uma área permeável, é essencial levar-se em conta o espaço disponível em torno do local que se pretende fazer o plantio.

Em sequência, depois de plantada a árvore é indispensável fazer a manutenção que favoreça o trânsito dos pedestres. Para isto, as podas recomendáveis no caso de árvores de calçadas são: a) a poda de formação, a qual é "usada na fase jovem da árvore, através do corte de galhos mais finos, visando à obtenção de uma copa bem conformada, respeitando 0 modelo arquitetônico da espécie e adequado às características do local de plantio" (MANUAL DE ARBORIZAÇÃO, 2011, p.61). b) a poda de manutenção, esta "usada na fase adulta da árvore, buscando evitar eventuais quebras de galhos secos ou mal formados ou para manter a convivência da copa com os equipamentos urbanos instalados no seu entorno" (MANUAL DE ARBORIZAÇÃO, 2011, p.61). Essas podas devem ser feitas por pessoas especializadas para não haver acidentes nem malefícios às árvores.

\section{VISOES E PENSAMENTOS}

Como integrante do Grupo de Estudos Sistêmicos do SemiÁrido do Nordeste GESSANE, é como uma obrigação falar dessa linha de pensamento que reflete no pensar 
complexo, ver mais que o aparente objetivo, valorizar o subjetivo, ir além do visto. Como estamos sobre a base de uma ciência abrangente como a Geografia, que tem como cunho maior de estudo a relação do homem com a terra em uma constante interação de ação entre o homem e a natureza, principalmente porque se entende que este ser denominado homem e parte dessa natureza, um faz parte do outro. "A ciência geográfica pressupõe que o mundo seja conhecido geograficamente, que o homem se sinta e saiba ligado à terra como ser chamado a se realizar em sua condição terrestre" (DARDEL, 2011, p, 33). E, a Ciências Geográficas sempre são renovadas com as novas ciências que compartilham do mesmo proposito, bem como ao tomar-se como referencia Morin, percebe-se que o mesmo expressa-se nessa mesma direção quando diz que "O desenvolvimento das ciências da Terra e da Ecologia revitalizam a Geografia, ciência complexa por princípio, uma vez que abrange a física terrestre, a biosfera e as implicações humanas[...] A geografia amplia-se em ciência da terra do homem" (MORIN, 2005, p. 28-29)

No estudo do verde presente em quintais, jardins e calçadas do município das Correntes, não se teve uma visão simplificadora ou separadora. Nesse contexto, procurou-se ver sempre a interação recíproca desses espaços, não apenas entre eles por se situarem nas residências urbanas, mas também com as demais vegetações que se coadunam com arborização urbana.

Tendo-se uma visão sistêmica que remete em pensar complexamente, deixa-se de ver, analisar, sintetizar as partes somente e procura-se entender o todo. Assim, segundo Capra apud Pena-Vega, "embora possamos distinguir as partes em todo sistema vivo, a natureza do todo é sempre diferente da simples soma das partes" (PENA-VEGA, 2003, p. 33). Pois, qualquer ponto de vegetação ou árvore faz parte das áreas verdes urbanas e essas, por sua vez, proporcionam conforto, bem estar, lazer e beleza a todo o Município.

\section{RESULTADOS}


Apresenta-se, a seguir, a tabela 1 que mostra os resultados em dados estatísticos da quantidade dos espaços destinados ao quintal, jardim e calçada das casas visitadas, calculado por rua estudada. Sendo OF para casas que não tem quintal ou usa o espaço com outra função, por exemplo: como área de serviço, e FQ para casas que o espaço destinado ao quintal é usado como o quintal útil. Já a sigla SJ representa casas que não têm jardim, porém grande parte das casas visitadas possuem plantas ornamentais no quintal ou em caqueras, mas esse fato não é levado em conta na montagem dos dados estatísticos. E a sigla CJ é usada para as casas que possuem jardim; SC para casa que não apresenta calçadas ou construíram sobre ela para cumprimentar a casa ou fazer alguma área fechada e CC para casas que apresentem calçadas com, no mínimo, um metro entre a casa e o meio fio.

Esse método serve para quantificar os espaços com a presença do verde presente nos locais de estudo, bem como se perceber como esses espaços são constituídos e utilizados em outras funções.

TABELA 1:

\begin{tabular}{|c|c|c|c|c|}
\hline $\begin{array}{c}\text { RUAS E } \\
\text { AVENIDAS }\end{array}$ & $\begin{array}{l}\text { EXTENÇÃO } \\
\text { Das Ruas }\end{array}$ & $\begin{array}{c}\text { QUINTAL } \\
\text { Casas visitadas }\end{array}$ & $\begin{array}{c}\text { JARDIM } \\
\text { Casas visitadas }\end{array}$ & $\begin{array}{c}\text { CALÇADA } \\
\text { Casas visitadas }\end{array}$ \\
\hline $\begin{array}{l}\text { Avenida } \\
\text { Raimundo } \\
\text { Calado }\end{array}$ & $280 m$ & $\begin{array}{l}16 \% \text { OF } \\
84 \% \text { FQ }\end{array}$ & $100 \%$ SJ & $100 \%$ CC \\
\hline $\begin{array}{l}\text { Rua Agamenon } \\
\text { Magalhães }\end{array}$ & $160 \mathrm{~m}$ & $\begin{array}{l}30 \% \text { OF } \\
70 \% \mathrm{FQ}\end{array}$ & $\begin{array}{l}50 \% \text { SJ } \\
50 \% \text { CJ }\end{array}$ & $\begin{array}{l}10 \% \text { SC } \\
90 \% \text { CC }\end{array}$ \\
\hline $\begin{array}{l}\text { Rua Barão de } \\
\text { Lucena }\end{array}$ & $106 \mathrm{~m}$ & $100 \% \mathrm{FQ}$ & $\begin{array}{l}25 \% \text { SJ } \\
75 \% \text { CJ }\end{array}$ & $\begin{array}{l}25 \% \text { SC } \\
75 \% \text { CC }\end{array}$ \\
\hline $\begin{array}{l}\text { Rua } \\
\text { Francisco } \\
\text { Santos }\end{array}$ & $240 m$ & $\begin{array}{l}50 \% \text { OF } \\
50 \% \text { FQ }\end{array}$ & $\begin{array}{l}90 \% \text { SJ } \\
10 \% \text { CJ }\end{array}$ & $100 \% \mathrm{CC}$ \\
\hline $\begin{array}{l}\text { Rua Cursino } \\
\text { Jacobina }\end{array}$ & $220 \mathrm{~m}$ & $\begin{array}{l}30 \% \text { OF } \\
70 \% \text { FQ }\end{array}$ & $\begin{array}{l}90 \% \text { SJ } \\
10 \% \text { CJ }\end{array}$ & $\begin{array}{l}20 \% \text { SC } \\
80 \% \text { CC }\end{array}$ \\
\hline $\begin{array}{l}\text { Avenida } \\
\text { Francisco de } \\
\text { Assis Calado }\end{array}$ & $160 m$ & $\begin{array}{l}25 \% \text { OF } \\
75 \% \text { FQ }\end{array}$ & $\begin{array}{l}50 \% \text { SJ } \\
50 \% \text { CJ }\end{array}$ & $100 \%$ CC \\
\hline $\begin{array}{l}\text { Rua João de } \\
\text { Deus Neto }\end{array}$ & $160 \mathrm{~m}$ & $\begin{array}{l}20 \% \text { OF } \\
80 \% \text { FQ }\end{array}$ & $\begin{array}{l}10 \% \text { SJ } \\
90 \% \text { CJ }\end{array}$ & $100 \%$ CC \\
\hline
\end{tabular}




\begin{tabular}{|c|c|c|c|c|}
\hline $\begin{array}{l}\text { Rua Joaquim } \\
\text { Nabuco }\end{array}$ & 320m & $\begin{array}{l}60 \% \text { OF } \\
40 \% \mathrm{FQ}\end{array}$ & $100 \%$ SJ & $100 \%$ CC \\
\hline $\begin{array}{l}\text { Rua José } \\
\text { Francisco dos } \\
\text { Santos }\end{array}$ & $110 \mathrm{~m}$ & $\begin{array}{l}10 \% \text { OF } \\
90 \% \text { FQ }\end{array}$ & $100 \%$ SJ & $\begin{array}{l}80 \% \text { SC } \\
20 \% \text { CC }\end{array}$ \\
\hline $\begin{array}{l}\text { Rua Quintino } \\
\text { Bocaiúva }\end{array}$ & $380 \mathrm{~m}$ & $\begin{array}{l}18,1 \% \text { OF } \\
81,9 \% \text { FQ }\end{array}$ & $\begin{array}{l}81,9 \% \text { SJ } \\
18,1 \% \text { CJ }\end{array}$ & $100 \%$ CC \\
\hline
\end{tabular}

Tabela 1: cálculo da extensão das ruas e dos espaços destinados ao verde nas residências urbanas. Fonte: Pesquisa de campo, 2012.

\section{Legenda:}

$\mathrm{OF}=$ casas com espaço destinado a quintal, sem função de quintal.

$\mathrm{FQ}=$ casas com espaço destinado a quintal com função de quintal.

$\mathrm{SJ}=$ casas que não possui jardim.

$\mathrm{CJ}=$ casas que possuem jardim.

$\mathrm{SC}=$ casas sem calçadas.

$\mathrm{CC}=$ casas com calçadas .

As principais frutíferas encontradas nos quintais são Goiabeira (Psiduim guajava), laranjeira (Citrus sinensis), bananeira (Musa spp) e mamoeiro (Carica papaya) entre outras espécies de frutíferas, hortaliças, etc. A tabela 2 mostra a heterogeneidade das espécies de plantas e cultivos em quintais. Sendo que os cuidados com as espécies vegetais dos quintais se restringem em irrigar, adubar e, em minoria, pulverizar contra insetos, fungos ou algum tipo de praga.

TABELA 2:

\begin{tabular}{lll}
\hline Principais plantas & Utilização & Motivos \\
Frutíferas & Alimentação Familiar & $\begin{array}{l}\text { Para servir de alimento para } \\
\text { a família e ajudar a } \\
\text { economizar. }\end{array}$ \\
Ervas medicinais & $\begin{array}{l}\text { Produção de Remédios } \\
\text { Caseiros }\end{array}$ & $\begin{array}{l}\text { Curar doenças sem precisar } \\
\text { ir ao médico, como gripes, } \\
\text { dor de cabeça, febres etc. } \\
\text { Auxiliar na alimentação }\end{array}$ \\
Temperos & Tempero para as Comidas & $\begin{array}{l}\text { Por que gosta/acha bonito } \\
\text { Plantas ornamentais }\end{array}$ \\
\hline
\end{tabular}

Tabela 2: Quintais Domésticos em Correntes-PE

Fonte: Pesquisa de campo, 2012. 
Já 30\% das ruas não apresentam jardim por unidade observada. Dos $70 \%$ das casas que tem jardim, apenas a Rua João de Deus Neto tem predominância de casas com espaço destinado a jardim. Na tabela 3 estão os principais tipos de plantas cultivadas nos jardins de Correntes, cuidados dedicados e motivos de cultivar um espaço desse na residência. Ressalta-se que o verde de uma residência também tem função terapêutica (terapia ocupacional), principalmente para pessoas idosas que já se encontram aposentadas, dedicando o seu tempo livre para cuidar da vegetação presente em seu lar.

\section{TABELA 3:}

\begin{tabular}{lll}
\hline $\begin{array}{l}\text { Principais Plantas } \\
\text { Flores e Roseiras }\end{array}$ & $\begin{array}{l}\text { Cuidados com as plantas } \\
\text { Regar, adubar e limpar. }\end{array}$ & $\begin{array}{l}\text { Importância } \\
\text { Deixa o ambiente mais } \\
\text { agradável, bonito e serve } \\
\text { como terapia ocupacional. }\end{array}$ \\
Plantas Ornamentais & Regar, adubar e limpar. & $\begin{array}{l}\text { Deixa o ambiente mais } \\
\text { agradável, bonito e serve } \\
\text { como terapia ocupacional. }\end{array}$ \\
Grama & Regar, adubar e limpar. & $\begin{array}{l}\text { Deixa o ambiente mais } \\
\text { agradável e bonito. }\end{array}$ \\
\hline
\end{tabular}

Tabela 2: Jardim e seus cuidados em Correntes, PE

Fonte: Pesquisa de campo, 2012.

No que se refere aos espaços das calçadas, o Município mostra muita deficiência relacionada ao plantio das árvores nas calcadas. Em grande parte, pela falta de planejamento urbano, levando ao fato de algumas árvores não terem sido plantadas no nível da superfície do solo sendo, então, construída uma mureta ao redor do tronco com a finalidade de diminuir a capacidade da árvore de absorver as águas das chuvas. Observou-se, ainda, que as arvores em geral não são podadas como deveriam e plantadas em pequenos espaços, dificultando a passagem das pessoas. 


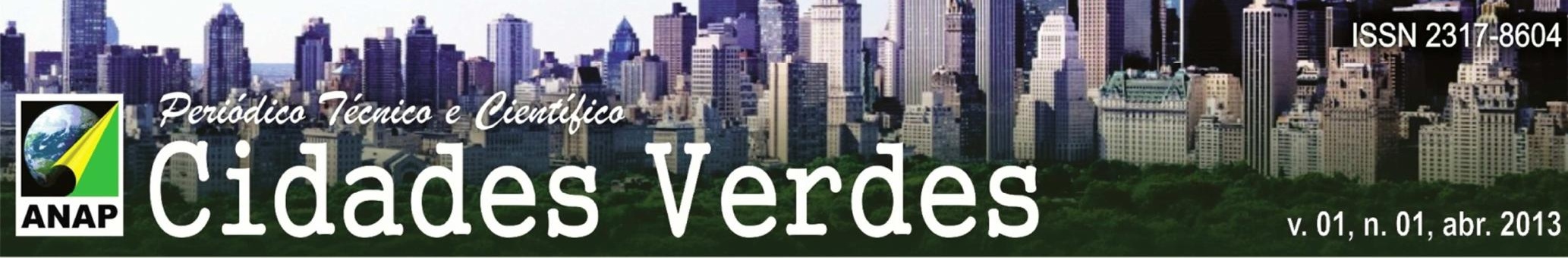

\section{CONCLUSÕES}

Ao final da pesquisa realizada sobre a arborização das calçadas, jardins e quintais da Cidade de Correntes, pode-se dizer que, tendo como base as Ciências Geográficas, apoiando-se numa visão sistêmica para pensar os problemas da arborização da cidade de maneira complexa, procurou-se compreender o todo atentando-se para a interação do verde urbano em geral, em vez de apenas se deter em uma ou outra parte.

Chegando-se as considerações que Correntes apresenta suas áreas residenciais deficientes em se tratando da arborização, principalmente no que se refere à arborização das calçadas, vários problemas foram levantados e entre eles cita-se, por exemplo, a falta de planejamento urbano e de conhecimento por parte da população sobre o tipo adequado de árvores para se plantar. Sabe-se que, para poder arborizar as calçadas é necessário levar em consideração alguns critérios técnicos como: tamanho da calçada, espaço que a arvore necessita para se desenvolver, os objetos que pertencem àquele lugar de modo que no futuro, não seja necessário à eliminação da espécie, que ela possa oferecer suas funções sem prejuízo, onde a população seja a mais beneficiada. Esse fato não é levado em conta no Município das Correntes, resultando em calçadas problemáticas do ponto de vista estrutural e arborização deficiente.

No que concerne ao espaço do quintal, verificou-se que o mesmo apresenta predominância de árvores frutíferas. Porém, algumas pessoas também tem a tradição de cultivar plantas medicinais para a prática da cura caseira e plantas ornamentais nesse espaço, por não ter mais área livre para cultivar, como um jardim. Observou-se, ainda, que são poucas as casas que têm o espaço destinado à função de jardim. E, como as pessoas gostam muito de roseiras, flores e plantas ornamentais por sua beleza ou superstição, as cultivam em caqueras, jarros, vasos, latas, bacias entre outros meios, no interior de suas residências.

Assim, torna-se necessário fazer uma extensão desta pesquisa com a finalidade de informar e esclarecer os correntenses sobre a importância e os benefícios do verde urbano, em especial ao de suas residências, de modo que os mesmos saibam como 
proceder com a arborização de suas casas e os principais tipos de plantas e árvores que se adequam para cultivar nos ambientes domiciliares, desde quintais, jardins e até as calçadas. Esse último tipo, ao mesmo tempo em que faz parte das casas, é parte integrante da rua.

\section{REFERÊNCIAS}

AMADOR, Maria Betânia Moreira. Sistemismo e sustentabilidade: questão interdisciplinar. São Paulo: Scortecci, 2011.

Companhia Energética de Minas Gerais. Manual de arborização. Belo Horizonte: Cemig/Fundação Biodiversitas, 2011. Disponível em: <www,comig.com.br/.../Manual-Arborização-Cemig-biodiversidade.pd...> acesso em 22/02/2012.

CHAVES, Ana Maria Severo; AMADOR, Maria Betânia Moreira. O verde urbano na paisagem agreste de correntes-pe: quintais, jardins e calçadas. Disponível em:<http://www.eng2012.org.br/>. Acesso em: 03 de novembro de 2012.

DARDEL, Eric. O homem e a terra: natureza da realidade geográfica. Tradução de Werther Holzer. São Paulo: Perspectiva: 2011.

LOBOLA, C. R.; DE ANGELLIS, B. L. D. Áreas verdes publicas: conceitos, usos e definições. Revista Ambiência. Guarapuva-PR. 2005. Disponível em: <http://www.revista.unicentro.br/index.php/ambieencia/article/download/.../185>. Acesso em: 17 maio 2012.

MORIN, Edgar: A cabeça bem-feita repensar a reformar o pensamento. Rio de Janeiro: Bertrand Brasil, 2005.

NETO, Evaldo Marques de Lima; SOUZA, Rosemeri Melo. Arborização urbana: Gênese e relevância no planejamento territorial. SOUZA, Rosemeri Melo: Território, planejamento e sustentabilidade. São Cristóvão: UFS, 2009.

PENA-VEGA, Alfredo. O despertar ecológico: Edgar Morin e a ecologia complexa. Tradução: Renato Carvalheira do Nascimento e Elimar Pinheiro do Nascimento. Rio de Janeiro: Garamond, 2003.

SANTOS, Arborização urbana: considerações: Disponível em <www.aultimaarcadenoe.com.br>. Acesso em 15 jul. 2012.

Secretaria do Meio Ambiente. Cartilha de arborização de calçadas. Disponível em: meioambiente@uberaba.mg.gov.br acesso em 08/09/2012. 